\title{
Characterizing land condition variability in Northern China from 1982 to 2011
}

\author{
Youzhi An $\cdot$ Wei Gao $\cdot$ Zhiqiang Gao
}

Received: 30 May 2013/ Accepted: 28 November 2013/Published online: 12 December 2013

(C) Springer-Verlag Berlin Heidelberg 2013

\begin{abstract}
For the last three decades, Northern China has been considered as one of the most sensitive areas regarding global environmental change. The integration of AVHRR GIMMS and MODIS NDVI data (1982-2011), of which for the overlapping period of 2000-2006 show good consistency, were used for characterizing land condition variability. The trends of standardized annually $\Sigma$ NDVI, temperature, precipitation and PDSI were obtained using a linear regression model. The results showed that Northern China has a general increase in greenness for the period $1982-2011(a=0.05)$. Also, annually $\Sigma$ NDVI is significantly correlated with temperature and precipitation data at the regional scale $(p<0.05)$, implying that temperature and precipitation are the dominant limiting factors for vegetation growth. Since the greening is not uniform, factors other than temperature and precipitation may contribute to greening in some areas, while the grassland and cropland ecosystem are becoming increasingly vulnerable to drought. The results of trend analysis indicate that greenness seems to be evident in most of the study areas.
\end{abstract}

\footnotetext{
Y. An $\cdot$ W. Gao

Key Laboratory of Geographic Information Science, Ministry of Education, East China Normal University, Joint Laboratory for Environmental Remote Sensing and Data Assimilation, ECNU and CEODE, CAS, Shanghai 20062, China e-mail: anyouzhi@163.com

W. Gao

Natural Resource Ecology Laboratory, Colorado State University, Fort Collins, CO 80523, USA

Z. Gao $(\bowtie)$

Yantai Institute of Coastal Zone Research, Chinese Academy of Science, Yantai 264003, China

e-mail: gaoland@gmail.com
}

Keywords NDVI $\cdot$ Land degradation $\cdot$ Linear trend analysis - Climate change

\section{Introduction}

Land degradation and desertification have become increasingly severe environmental and socio-economic problems throughout the world. According to the United Nations Convention to Combat Desertification (UNCCD 1994), desertification is defined as "land degradation in arid, semi-arid and dry sub-humid areas resulting from various factors, including climatic variations and human activities". Two crucial factors related to the cause of land degradation are water availability and biome availability. Climate change and other reasons (such as topography) can lead to precipitation changes which subsequently affect vegetation productivity which is additionally deteriorated by human activities such as forestation or deforestation. Although the causes of land degradation in Northern China are now nearly consistent, the discussion of the relative importance of climate change versus human activities remains a contentious dispute issue (Yang et al. 2005; Wang et al. 2008).

Problems of land degradation and desertification have been identified worldwide, e.g. Africa south of the equator, South-East Asia and south China, north-central Australia, the Pampas and swaths of the Siberian and North American taiga (Bai et al. 2008). China is one of the most seriously affected countries by land degradation and desertification, as a result of intense meteorological phenomenon such as sandstorms, especially in Northern China (Wang et al. 2008). So, it is very important to combat desertification in Northern China. Recent studies have suggested mixed trends of vegetation in Northern China, in selected case 
studies (Liu et al. 2010; Cao et al. 2011; Zhu et al. 2011; Mu et al. 2012; Wang et al. 2012), at a national scale (Yang et al. 2005; Wang et al. 2008; Bai and Dent 2009; Xu et al. 2012) and even at continental to global scale (Bai et al. 2008; Piao et al. 2011; Fensholt et al. 2012). By the end of 2009, China had a total desertification land area of $2,623,700 \mathrm{~km}^{2}$ accounting for $27.33 \%$ of the national territory and distributed in 508 counties (banners, countylevel cities) of 18 provinces (autonomous regions, municipalities) of China, i.e. Beijing, Tianjin, Hebei, Shanxi, Inner Mongolia, Liaoning, Jilin, Shandong, Henan, Hainan, Sichuan, Yunnan, Tibet, Shaanxi, Gansu, Qinghai, Ningxia and Xinjiang (State Forestry Administration 2011).

Over the past 30 years, satellite data have been widely used to characterize the changes in land condition variability. The normalized difference vegetation index (NDVI), as a data for assessing spatio-temporal change of variables related to vegetation greenness and land degradation, has been extensively used at a regional or global scale (Symeonakis and Drake 2004; Olsson et al. 2005; Hickler et al. 2005; Fensholt et al. 2012). Remotely sensed imagery is available in time series with medium to coarse spatial resolution for vegetation dynamics. So far, some case studies using NDVI time series data acquired by a variety of satellite sensors have been conducted for temporal analysis, e.g. Advanced Very High Resolution Radiometer (AVHRR) Global Inventory Modeling and Mapping Studies (GIMMS) NDVI dataset (Nemani et al. 2003; de Jong et al. 2011; Huber et al. 2011; Fensholt et al. 2012; Mao et al. 2012), the Spinning Enhanced Visible and Infrared Imager (SEVIRI) sensor onboard the geostationary satellite Meteosat Second Generation (MSG) (Fensholt et al. 2006), VEGETATION sensor onboard the SPOT satellites (SPOT/VGT) based NDVI (Liu et al. 2010; Martínez et al. 2011; Yin et al. 2011; Dong et al. 2011; Zhang et al. 2013), moderate resolution imaging spectroradiometer sensor on board the Terra platform (MODIS/ Terra) (Fensholt et al. 2009; Yao et al. 2011; Mu et al. 2012; Tian et al. 2012) and others (e.g. Hyperion) (Zhang et al. 2012). The AVHRR GIMMS NDVI time series have dominated the field of large-scale monitoring of vegetation due to the long time series available (Bégué et al. 2011; Fensholt et al. 2012). For the purposes of this study, time series of the AVHRR GIMMS NDVI (1982-2006) and Terra MODIS NDVI (2007-2011) are selected to obtain the integrated 30 years long time series data.

In this study, we will investigate the land condition variability in Northern China using annually $\Sigma$ NDVI and climatic data. Our purpose is to: (1) provide satellite-based observation evidence of recent land condition variability in semi-arid and arid regions of the Northern China; and (2) analyze the spatio-temporal relationships between annually $\Sigma$ NDVI and annual climatic data anomalies.

\section{Data and methods}

Study area

The study area spans $31^{\circ}-54^{\circ} \mathrm{N}$ in latitude and $73^{\circ}-136^{\circ} \mathrm{E}$ in longitude with a total area of $499.5 \mathrm{~km}^{2}$. Administratively, Northern China includes 13 provinces of Heilongjiang, Jilin, Liaoning, Inner Mongolia, Beijing, Tianjin, Hebei, Shanxi, Shaanxi, Ningxia, Gansu, Qinghai and Xinjiang (Fig. 1). The whole Northern China region is divided into three zones (Northeast China, North China and Northwest China) (Fig. 1). The climate is dominantly semi-arid with annual precipitation ranging from 15 to $1,146 \mathrm{~mm}$ (mean annual precipitation of $382 \mathrm{~mm}$ ) while most precipitation volume occurs during the months June to September. The environment in this region is vulnerable to climate variability due to intense interannual variations in precipitation.

Satellite data

\section{AVHRR GIMMS 15-day composite NDVI data}

The widely used AVHRR GIMMS NDVI data product with a spatial resolution of $8 \times 8 \mathrm{~km}$ was selected in this study from 1982 to 2006. Data were acquired from the Global Land Cover Facility (http://www.landcover.org/ data/gimms/). The dataset is derived from imagery obtained from the AVHRR instrument onboard the NOAA satellite series 7, 9, 11, 14, 16 and 17. The NDVI dataset has been corrected for calibration, view geometry, volcanic aerosols, and other effects not related to vegetation change, as well as, for atmospheric corrections (Tucker et al. 2005). Only AVHRR GIMMS NDVI pixels with good value $($ flag $=0)$ are included for correlation analysis with MODIS NDVI data to construct a long time series (1982-2011) for trend analysis.

\section{Terra MODIS monthly composite NDVI data}

The MODIS onboard the Earth Observation System (EOS) Terra satellites were launched on December 1999. Many of MODIS data products (e.g. NDVI) have a great advantage in a wide range of scientific research from the medium to large scale. The MOD13C2 data covering from 2000 to 2011 were downloaded from the USGS Land Processes Distributed Active Archive Center (LP DAAC, http://lads web.nascom.nasa.gov/data/search.html). The MOD13C2 (collection 5) data are $0.05^{\circ}$ monthly product which is generated using the gridded monthly 1-km MODIS NDVI product (MOD13A3), and temporally aggregated using a weighted average to create a calendar-month composite (Solano et al. 2010). The MOD13C2 vegetation product 
Fig. 1 Location of the study area (where, Northeast ChinaNE. China, North China-N. China, Northwest China-NW. China)

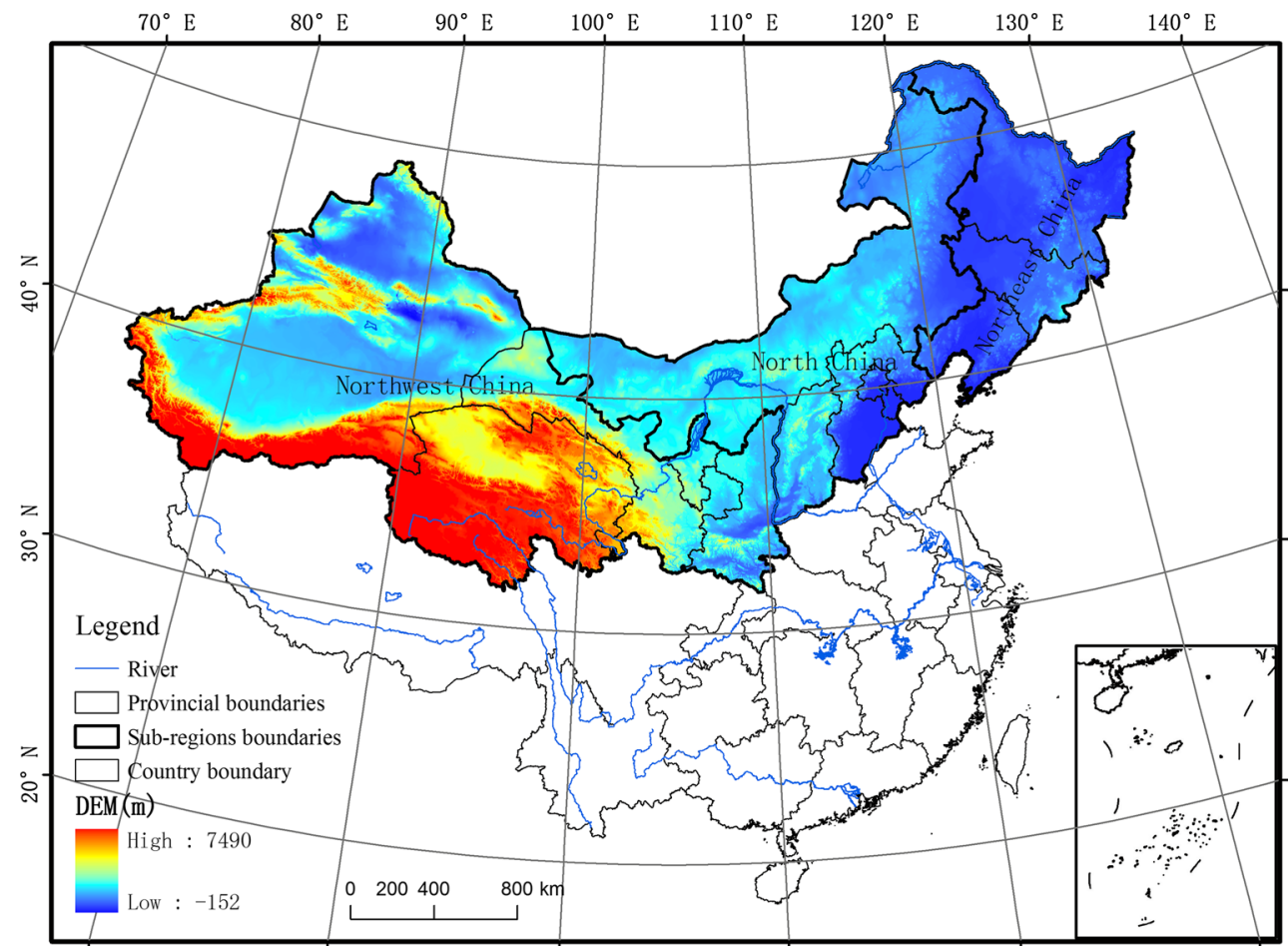

contains a data quality assessment product (QA-data) that holds information on the overall usefulness and cloud conditions on a per-pixel basis. More specific explanations of MOD13C2 VI pixel reliability can be found at MODIS_UsersGuide (Solano et al. 2010).

\section{Climatic data}

The precipitation and temperature data were offered by the Climate Research Unit (CRU), University of East Anglia, UK. CRU dataset used an interpolation method based on the set of stations available for monthly precipitation and temperature (Mitchell and Jones 2005), which is provided as a monthly sum at a $0.5^{\circ} \times 0.5^{\circ}$ spatial resolution for the period 1901-2011. The CRU precipitation and temperature dataset cover the full period of the integrated 30 years long time series data. Several global datasets provide spatially disaggregated estimates of precipitation for Northern China, e.g. GPCP (Global Precipitation Climatology Project) with a $2.5^{\circ} \times 2.5^{\circ}$ coarse spatial resolution. In this study, monthly accumulated precipitation and temperature data derived from CRU were used and this dataset has also been used in many studies (Helldén and Tottrup 2008; Piao et al. 2011; Xu et al. 2012).

The Palmer Drought Severity Index (PDSI) data are popular in the meteorological, agricultural and hydrological drought studies and also include runoff and soil moisture. In this study, monthly PDSI data at a $2.5^{\circ} \times 2.5^{\circ}$ spatial resolution for the period 1982-2006 were obtained from the University Corporation for Atmospheric Research (Dai 2011).
Land cover data

Land covers data (MCD12Q1-IGBP 2009) are shown in Fig. 2 as a reference for further analyzed $\Sigma$ NDVI for different land cover classes. Also, land cover data with a $500 \mathrm{~m}$ resolution have been resampled into a geographic type of approximately $8 \times 8 \mathrm{~km}$ resolution in order to match with $\Sigma$ NDVI.

Data processing methods

\section{Data post-processing}

Impacts of land degradation lead to losses in land productivity. A simple method uses annually integrated NDVI ( $\Sigma$ NDVI) as a proxy for vegetation productivity (Fensholt and Rasmussen 2011). The greenness indices ( $\Sigma$ NDVI) which are one of the major driving forces for biomass availability can perform adequately well as the sensitive indicators of land condition variability (greenness and land degradation) in arid, semi-arid and dry subhumid areas (Prince et al. 1998; Bai et al. 2008; Bai and Dent 2009; Fensholt and Rasmussen 2011). Also, annually summed precipitation, annually averaged temperature and PDSI are used for the 26 years series of data $(\mathrm{Xu}$ et al. 2012).

The analysis were restricted to include only those parts of the study regions that had a long-term (1982-2011) mean monthly NDVI value between 0.1 and 0.5 (Helldén and Tottrup 2008). Because the low NDVI values in our 
Fig. 2 Land cover map of Northern China for 2009. Locations for further analyses are overlaid

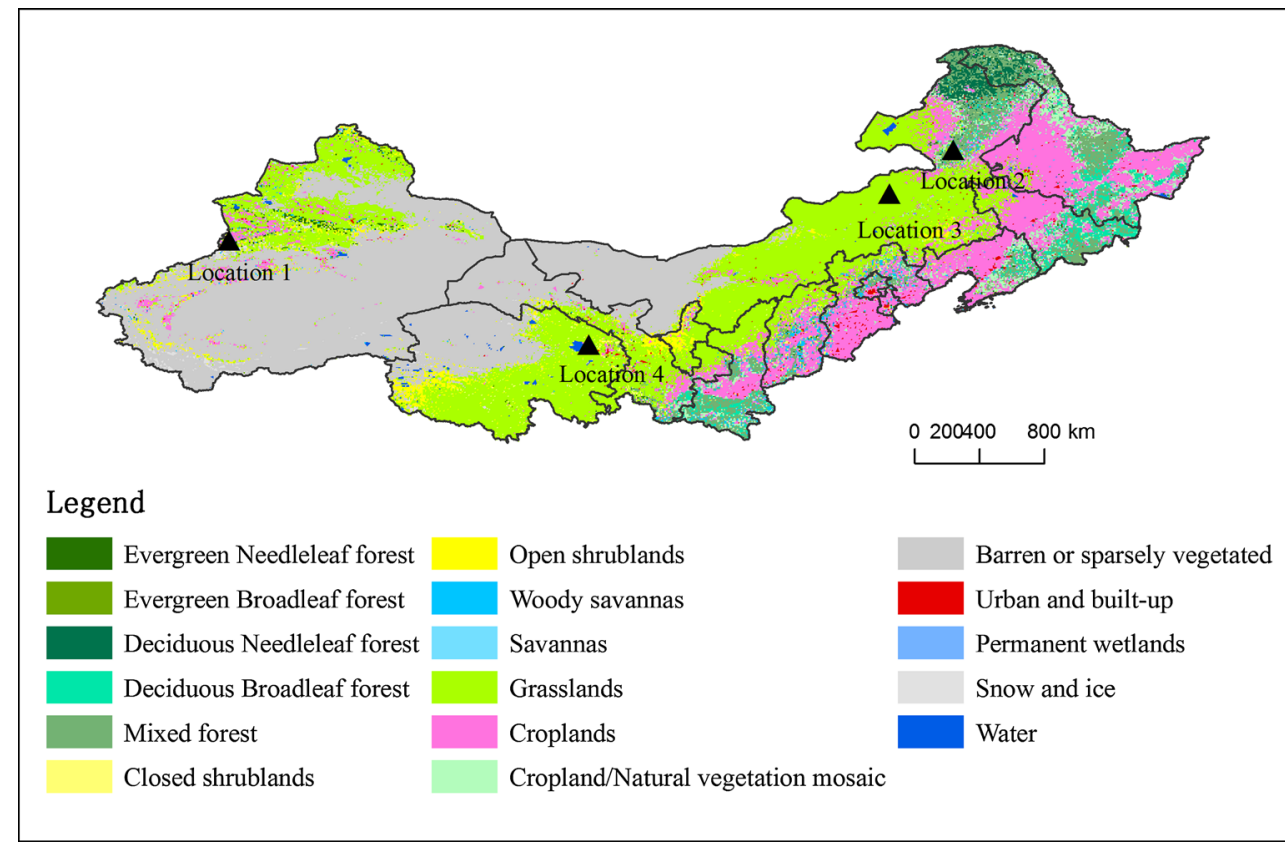

analysis would be uncertain. In order to further reduce the influence from clouds, the original 15-day temporal resolution AVHRR GIMMS NDVI data were aggregated monthly by a maximum value composite approach (MVC). MODIS NDVI products in HDF format were reprojected to the WGS-84 coordinate system with nearest-neighbor resampling method by the MODIS Reprojection Tool v4.0 (MRT) and saved as the GeoTIFF format for further analysis. Per-pixel QA information in both the AVHRR GIMMS and MODIS NDVI products was used to remove the NDVI data without confidence (contaminated by cloud or snow/ice). Then, a simple temporal filter was applied to gap-fill the missing integrating AVHRR GIMMS and MODIS NDVI data (Xiao et al. 2003; Fensholt et al. 2009). Owing to the lack of the first month Terra MODIS data in the observation year 2000, the average values for the first month of 2001-2011 are used to replace it. MODIS NDVI data have been resampled to match the GIMMS NDVI resolution by spatial averaging for calculating NDVI. For comparing the trends of $\Sigma$ NDVI and climatic data (precipitation and temperature), monthly NDVI and CRU climatic data are converted into annual time series. Further, CRU climatic data with a $0.5^{\circ}$ resolution have been resampled into a geographic type of $\sim 8 \times 8 \mathrm{~km}$ resolution to match with $\Sigma$ NDVI.

\section{Methodology}

The time integrated NDVI and climatic data were standardized with $Z$-score method, which could be compared across regions at the same scale (Helldén and Tottrup 2008; $\mathrm{Xu}$ et al. 2012). $z(i)=\frac{x(i)-\mu}{\sigma}$

where $z(i)$ is the standardized result of NDVI or climatic data, $x(i)$ is the data to be standardized, $\mu$ is the mean of the data, $\sigma$ is the standard deviation of the data.

The trend of annually $\Sigma$ NDVI and climatic data was obtained from the linear regression model with time as the independent variable while $\Sigma$ NDVI and climatic data as the dependent variable for the period 1982-2011. The linear regression model is a simple and robust way to analyze long-term trends in $\Sigma$ NDVI and climatic data (Wang et al. 2010; Piao et al. 2011).

$y=a+b t+\varepsilon$

where $y$ represents annually $\Sigma$ NDVI, $t$ is year or climate variable, $a$ and $b$ are coefficients, and $\varepsilon$ is the residual error.

The non-parametric Mann-Kendall (MK) significance method has been commonly applied to the time series trend test for the vegetation (Fensholt et al. 2009; Tabari et al. 2011), so it was used to test the time series trends in this study. The MK test statistic $S$ is calculated using the formula:

$S=\sum_{k=1}^{n-1} \sum_{j=k+1}^{n} \operatorname{sgn}\left(x_{j}-x_{k}\right)$

where $x_{j}$ and $x_{k}$ are the annual values in years $j$ and $k, j>k$, respectively. Where sgn is the sign function:

$\operatorname{sgn}\left(x_{j}-x_{k}\right)=\left\{\begin{array}{cl}+1 & \text { if }\left(x_{j}-x_{k}\right)>0 \\ 0 & \text { if }\left(x_{j}-x_{k}\right)=0 \\ -1 & \text { if }\left(x_{j}-x_{k}\right)<0\end{array}\right.$ 
where variance $\operatorname{Var}(S)$ is calculated by

$\operatorname{Var}(S)=\frac{\left[n(n-1)(2 n+5)-\sum_{p=1}^{q} t_{p}\left(t_{p}-1\right)\left(2 t_{p}+5\right)\right]}{18}$

where $n$ is the number of data points, $q$ is the number of tied groups and $t_{p}$ denotes the number of ties of extent $p$. The standard normal test statistic $Z$ is computed as

$Z=\left\{\begin{array}{cc}\frac{S-1}{\sqrt{\operatorname{Var}(S)}} & \text { if } S>0 \\ 0 & \text { if } S=0 \\ \frac{S+1}{\sqrt{\operatorname{Var}(S)}} & \text { if } S<0\end{array}\right.$

A positive slope $(Z \geq 1.96)$ represents a significant increase $(\alpha=0.05)$ in $\Sigma$ NDVI while negative slopes $(Z \leq-1.96)$ indicate a significant decrease $(\alpha=0.05)$.

\section{Results and discussions}

Consistency test

On pixel-by-pixel basis, a high correlation between the GIMMS NDVI dataset and the MODIS NDVI dataset for the overlapping period 2000-2006 can be observed for most areas across the study regions (Fig. 3a). Overall, the two data have a good consistency for the selected region (Fig. 3b). However, GIMMS NDVI displays higher peaks during the growing season than MODIS NDVI. A scatterplot of monthly observations of GIMMS and MODIS NDVI for 2,025 pixels selected randomly in Northern China (Fig. 3c) shows high correlation $\left(R^{2}=0.92\right)$ and low RMSE $($ RMSE $=0.072)$. The high positive correlation between the GIMMS and MODIS NDVI dataset for the overlapping period 2000-2006 gives confidence that a long time series of NDVI trend is robust for 30 years (1982-2011).

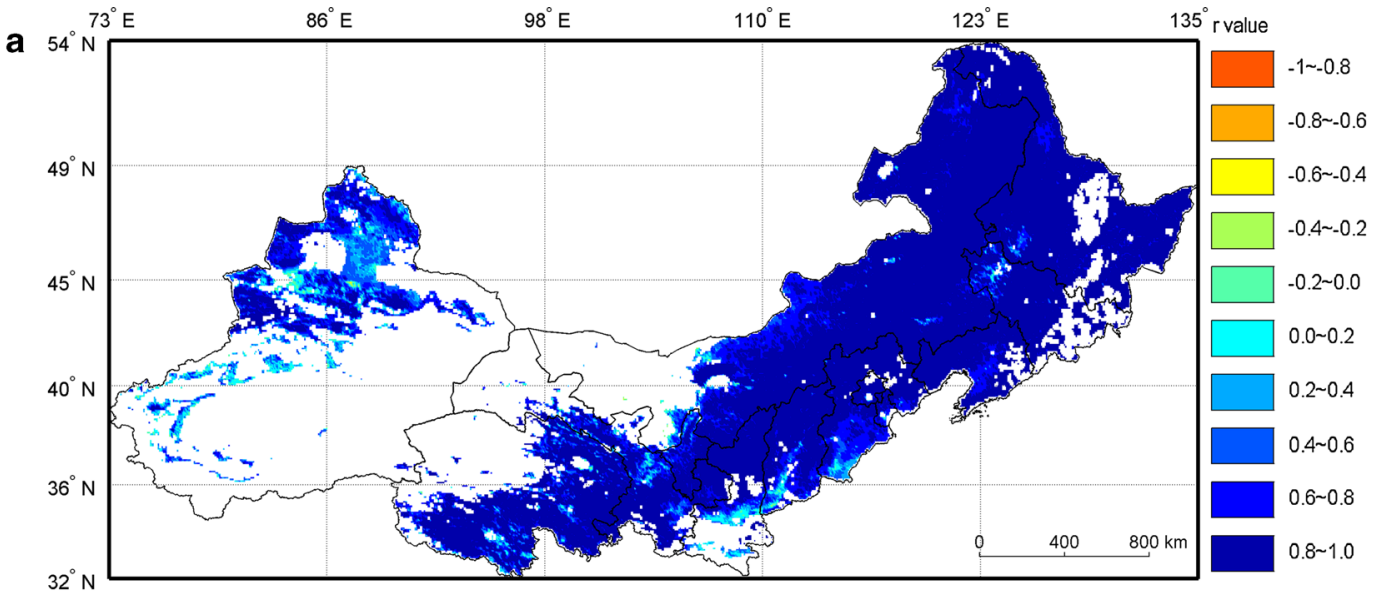

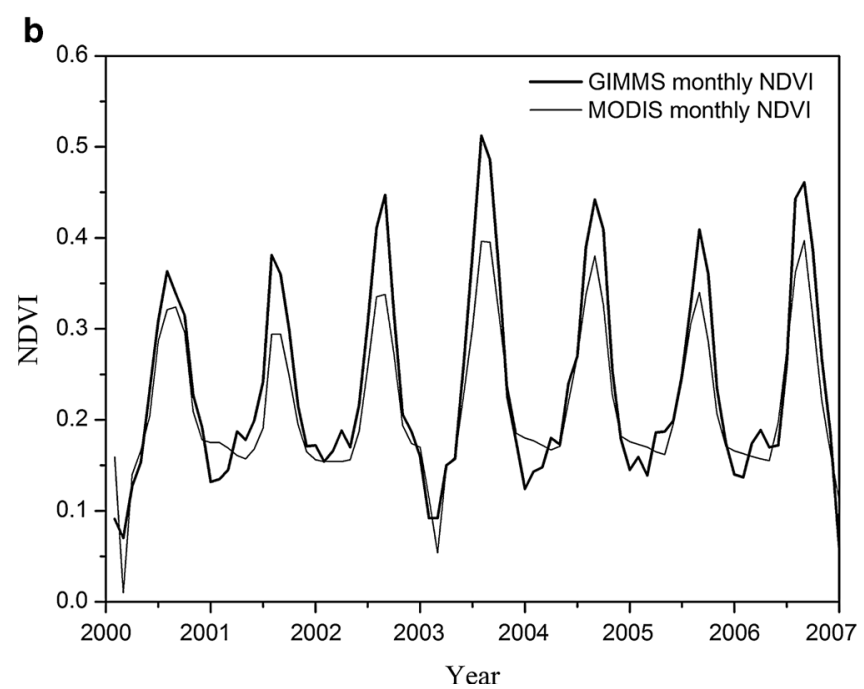

Fig. 3 Consistency test for GIMMS and MODIS NDVI. a Map of $r$ values for monthly GIMMS NDVI correlated against monthly MODIS NDVI (2000-2006). b Time series of monthly GIMMS and MODIS NDVI (2000-2006) for selected regions $\left(114.8^{\circ} \mathrm{E}, 43.0^{\circ} \mathrm{N}\right)$.

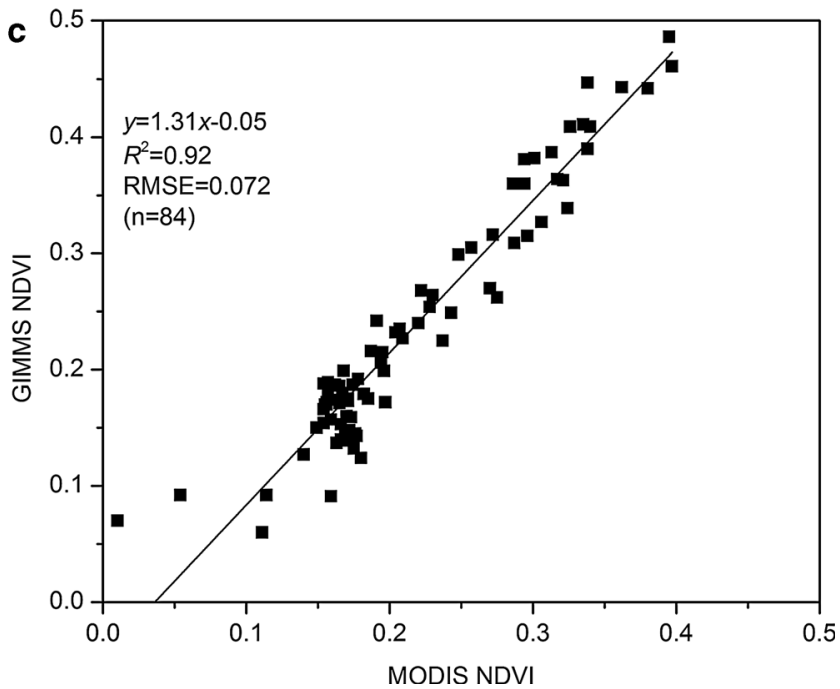

c Scatterplot of monthly GIMMS NDVI against monthly MODIS NDVI (2000-2006) for 2025 pixels randomly selected in Northern China $\left(114.8^{\circ} \mathrm{E}, 43.0^{\circ} \mathrm{N}\right)$ 
Fig. 4 Maps of linear regression temporal trend analysis (1982-2011) a $\Sigma \mathrm{NDVI}$, b precipitation, $\mathbf{c}$ temperature, d PDSI $(\alpha=0.05)$
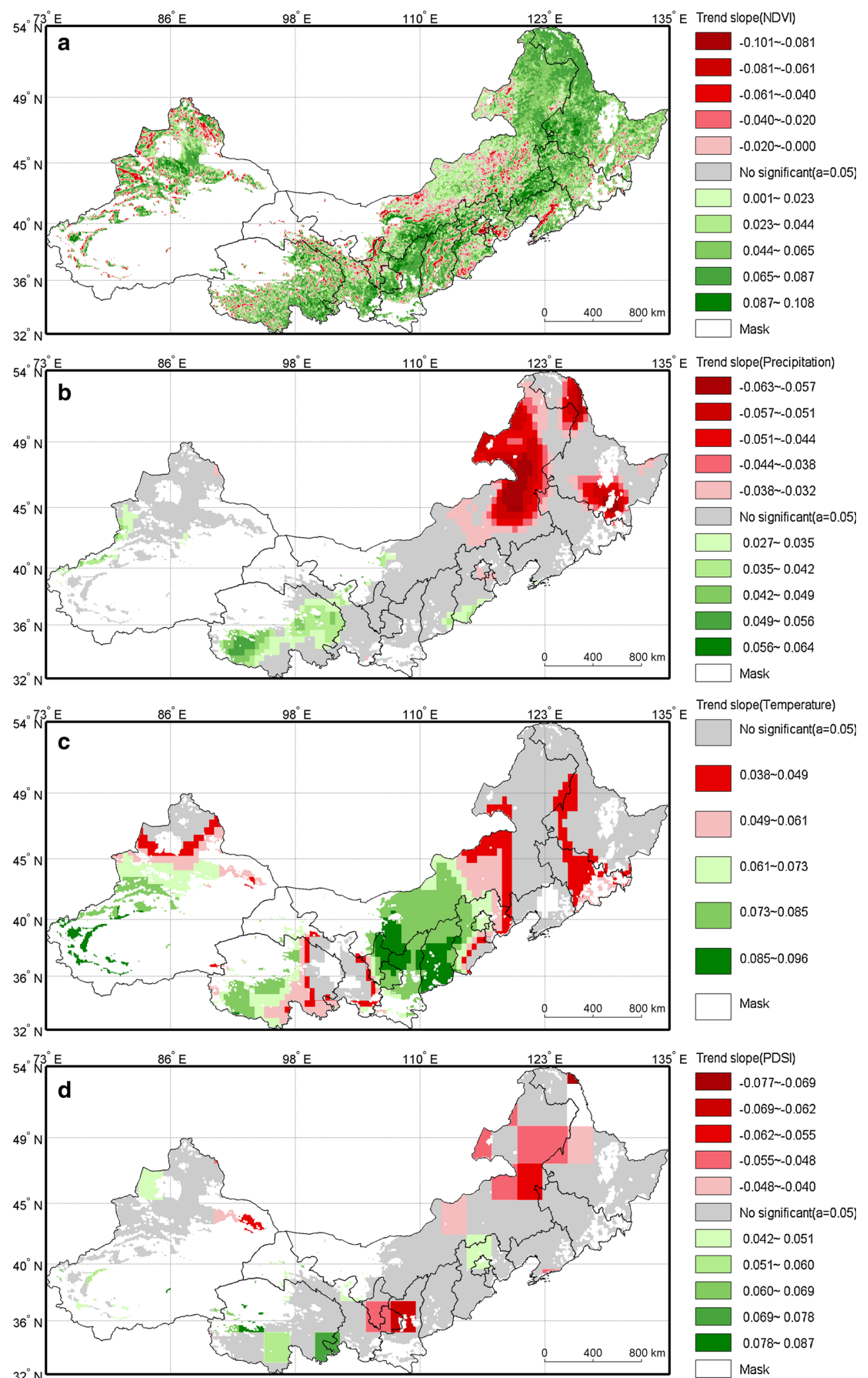

Trends in $\Sigma$ NDVI and annual climatic data

1982-2011. The pixel-to-pixel trend statistics with significant positive/negative regression slopes are reported for three regions in Table 1.
The significant trends in $\Sigma$ NDVI and annual climatic data against time were derived (Fig. 4) for a period of 
Figure 4a shows the $\Sigma$ NDVI trend estimated from the linear regression of the full period (1982-2011) annual time series in Northern China. A positive trend in $\Sigma$ NDVI indicates greenness, while a negative trend shows land degradation. More than $42 \%$ of the study area shows a positive trend in $\Sigma$ NDVI, and only $3.7 \%$ of the study area exhibits a statistically significant negative trend in Table 1. Across all regions in the study, the significant positive trend in $\Sigma$ NDVI is found in most of the areas; the greenness with a belt of high positive slope values across Daxingan Mountains, eastern Liaoning, and the Loess Plateau extends to the Qilian Mountains and southern Qinghai, and Xinjiang, Tianshan Mountains. But local land degradation was found in Liao River Plain, Inner Mongolia, Beijing, Tianjin, Hebei southern, central Shanxi, and Xinjiang. So a general "greening up" in $\Sigma$ NDVI can be observed over most of the Northern China for the period 1982-2011. A similar result is also found by other studies (de Jong et al. 2011; Fensholt et al. 2012; Xu et al. 2012).

From the maps of the annual sums of precipitation trend analysis (Fig. 4b), most of the region does not change significantly in annual precipitation over most of the Northern China for the period 1982-2011. A significant increase in Qinghai Province and a significant reduction in the northern Inner Mongolia and Heilongjiang Province can be found. A significant positive trend in the annual sums of precipitation was found for a total of $3.0 \%$ in the Northern China with large differences in different regions (0.3\% in NE China, $0.4 \%$ in N China and $6.9 \%$ in NW China), whereas $12.8 \%$ (14.2\% in NE China, $25.6 \%$ in $\mathrm{N}$ China and $0.0 \%$ in NW China) of the pixels being characterized by negative significant trends at a $5 \%$ confidence level. In fact, there is recent evidence of change in precipitation since the 1960s (Piao et al. 2011; Song et al. 2011).

The spatial distribution of temperature linear regression temporal trend is presented in Fig. 4c. Most study regions in Table 1 show greater and statistically significant increases $(53.8 \%)$ in temperature. Particularly, the Loess Plateau region experiences greater warming than other regions. The increased greenness feedback is important, and most studies that discuss these findings are very important in arid and semi-arid regions (Wang et al. 2010; Peng et al. 2011). Furthermore, Piao et al. (2011) find that increasing temperature could enhance spring and autumn greenness because of the sensitivity of temperature to vegetation growth in spring and autumn.

Figure $4 \mathrm{~d}$ displays the linear regression temporal trend of PDSI. The result in Table 1 shows more areas decreasing $(12.7 \%)$ than increasing $(6.6 \%)$, which is relatively similar to precipitation for most of study areas, both statistically and spatially. The results described by
Table 1 Trend statistics for $\Sigma$ NDVI, annual precipitation, temperature, and PDSI linear trend analysis 1982-2011 $(\alpha=0.05)$

\begin{tabular}{|c|c|c|c|c|}
\hline Number of observations & $\begin{array}{l}\text { NE } \\
\text { China }\end{array}$ & $\begin{array}{l}\mathrm{N} \\
\text { China }\end{array}$ & $\begin{array}{l}\text { NW } \\
\text { China }\end{array}$ & $\begin{array}{l}\text { Northern } \\
\text { China }\end{array}$ \\
\hline $\begin{array}{l}\text { Total pixels }(n) \Sigma \text { NDVI } \\
\text { mean between } 0.1 \text { and } 0.5\end{array}$ & 15,617 & 26,787 & 28,638 & 71,042 \\
\hline $\begin{array}{l}\Sigma \text { NDVI positive regression } \\
\text { slope }(n)\end{array}$ & 7,225 & 9,843 & 13,321 & 30,389 \\
\hline $\begin{array}{l}\Sigma \text { NDVI negative regression } \\
\text { slope }(n)\end{array}$ & 486 & 766 & 1,392 & 2,644 \\
\hline $\begin{array}{l}\Sigma \text { NDVI positive regression } \\
\text { slope }(\%)\end{array}$ & 46.3 & 36.7 & 46.5 & 42.8 \\
\hline $\begin{array}{l}\Sigma \text { NDVI negative regression } \\
\text { slope }(\%)\end{array}$ & 3.1 & 2.9 & 4.9 & 3.7 \\
\hline $\begin{array}{l}\text { Precipitation positive } \\
\text { regression slope }(n)\end{array}$ & 44 & 117 & 1,986 & 2,147 \\
\hline $\begin{array}{l}\text { Precipitation negative } \\
\text { regression slope }(n)\end{array}$ & 2,212 & 6,860 & 0 & 9,072 \\
\hline $\begin{array}{l}\text { Precipitation positive } \\
\text { regression slope }(\%)\end{array}$ & 0.3 & 0.4 & 6.9 & 3.0 \\
\hline $\begin{array}{l}\text { Precipitation negative } \\
\text { regression slope }(\%)\end{array}$ & 14.2 & 25.6 & 0.0 & 12.8 \\
\hline $\begin{array}{l}\text { Temperature positive } \\
\text { regression slope }(n)\end{array}$ & 1,440 & 15,898 & 20,862 & 38,200 \\
\hline $\begin{array}{l}\text { Temperature negative } \\
\text { regression slope }(n)\end{array}$ & 0 & 0 & 0 & 0 \\
\hline $\begin{array}{l}\text { Temperature positive } \\
\text { regression slope }(\%)\end{array}$ & 9.2 & 59.3 & 72.8 & 53.8 \\
\hline $\begin{array}{l}\text { Temperature negative } \\
\text { regression slope }(\%)\end{array}$ & 0 & 0 & 0 & 0 \\
\hline $\begin{array}{l}\text { PDSI positive regression } \\
\text { slope }(n)\end{array}$ & 0 & 1,153 & 3,551 & 4,704 \\
\hline $\begin{array}{l}\text { PDSI negative regression } \\
\text { slope }(n)\end{array}$ & 1,295 & 4,790 & 2,924 & 9,009 \\
\hline $\begin{array}{l}\text { PDSI positive regression } \\
\text { slope }(\%)\end{array}$ & 0.0 & 4.3 & 12.4 & 6.6 \\
\hline $\begin{array}{l}\text { PDSI negative regression } \\
\text { slope }(\%)\end{array}$ & 8.3 & 17.9 & 10.2 & 12.7 \\
\hline
\end{tabular}

Xu et al. (2012) and Mohammat et al. (2012) were associated with the PDSI trends in the study areas.

All four indexes show a mixed trend during the study periods. As shown in Fig. $4 \mathrm{~b}$ and d, the result leads to drought trend information in Fig. $4 \mathrm{~d}$ more consistent with Fig. $4 \mathrm{~b}$. The temperature shows a dramatic increase during 1982-2011. Comparatively, areas of significant changes in precipitation and PDSI are mainly distributed in Inner Mongolia and Qinghai Province, which appear to somewhat increase, although the area of the increase is little.

The trend regression slope value statistics calculated per land cover class for pixels are provided in Table 2. Since few pixels are in the land cover classes "evergreen broadleaf forest" and "savannas", so they are incorporated into the land cover classes "evergreen forest" and "woody 
Table 2 Trend statistics for $\Sigma$ NDVI linear trend analysis 1982-2011 $(a=0.05)$ for major land cover classes (IGBP)

\begin{tabular}{lccccc}
\hline Land cover class (IGBP) & $\begin{array}{l}\Sigma \text { NDVI } \\
(n)(a=0.05)\end{array}$ & $\begin{array}{l}\Sigma \text { NDVI } \\
\text { slope }>0(\%)\end{array}$ & $\begin{array}{l}\Sigma \text { NDVI } \\
\text { slope }<0(\%)\end{array}$ & $\begin{array}{l}\Sigma \text { NDVI slope } \\
\text { value mean }\end{array}$ & $\begin{array}{l}\Sigma \text { NDVI standard } \\
\text { deviation }\end{array}$ \\
\hline Evergreen forest & 270 & 89.6 & 10.4 & 0.058 & 0.042 \\
Deciduous Needleleaf forest & 684 & 99.9 & 0.1 & 0.068 & 0.007 \\
Deciduous broadleaf forest & 618 & 95.3 & 4.7 & 0.061 & 0.029 \\
Mixed forest & 2,534 & 97.2 & 2.8 & 0.064 & 0.024 \\
Closed shrublands & 424 & 93.9 & 6.1 & 0.061 & 0.035 \\
Open shrublands & 1,170 & 87.4 & 12.6 & 0.062 & 0.045 \\
Woody savannas/savannas & 653 & 94.6 & 5.4 & 0.058 & 0.033 \\
Grasslands & 13,983 & 92.6 & 7.4 & 0.061 & 0.036 \\
Croplands & 8,904 & 94.1 & 5.9 & 0.062 & 0.034 \\
Cropland/natural vegetation mosaic & 2,056 & 95.1 & 4.9 & 0.037 & 0.030 \\
Barren or sparsely vegetated & 2,181 & 77.2 & 22.8 & 0.055
\end{tabular}

savannas/savannas" in the statistical analysis, respectively. Different types of land cover classes have an impact on the linear slope values of $\Sigma$ NDVI trends. Overall, the greenness in all vegetation types significantly increases $(a=0.05)$. Land cover class "deciduous needleleaf forest" has the highest regression slope mean values $(0.068)$ followed by "mixed forest" (0.064), "woody savannas/savannas" (0.062), and "cropland/natural vegetation mosaic" (0.062). Land cover class "barren or sparsely vegetated" has the lowest regression slope mean values (0.037). Also, a regression slope standard deviation value of 0.055 indicates very large interclass variations.

The relationship of $\Sigma$ NDVI and annual climatic data

The correlation values between annually $\Sigma$ NDVI and precipitation for the period 1982-2011 are shown in Fig. 5a. Histogram shows correlation coefficients calculated between $\Sigma$ NDVI and precipitation for Northern China (Fig. 6a). The Pearson correlation coefficient indicates the relationship between $\Sigma$ NDVI and precipitation for the studied time period ranged from -0.667 to 0.799 . $\Sigma$ NDVI and precipitation were positively correlated, and high correlation coefficient areas are mainly located in central Inner Mongolia, central Gansu, and Northern Xinjiang. Negatively related areas are mainly distributed in parts of Heilongjiang Province, Inner Mongolia and Qinghai Province. $\Sigma$ NDVI versus precipitation significant $r$ value only counts for $13.1 \%$ in the whole Northern China (Figs. 5a, 6a). Several previous studies have shown a positive relationship between $\Sigma$ NDVI and precipitation (Helldén and Tottrup 2008; Duan et al. 2011; Mu et al. 2012; Bayramov et al. 2012).

The spatial correlation map and histogram between $\Sigma$ NDVI and temperature are shown in Figs. $5 b$ and $6 b$. The strongest correlations are obtained between $\Sigma$ NDVI and temperature during the three decades, with the largest increases found for the Loess Plateau, Qinghai and Southern Xinjiang. The increased greenness in the Loess Plateau appears to be influenced more by increases in temperature. This has been discussed in a number of studies (Piao et al. 2011; Peng et al. 2011; Duan et al. 2011; Liu et al. 2011; Mao et al. 2012).

A correlation analysis (Fig. 5c) was conducted to further examine $\Sigma$ NDVI-PDSI relationships. Figure 6c illustrates the histogram between $\Sigma$ NDVI and PDSI for Northern China. It was found that the positive correlation coefficients are relatively high at approximately $95 \%$ confidence level. Evidence has recently indicated that there is land degradation caused by drought in the study areas (Mohammat et al. 2012; Liu and Wang 2012).

From the correlation analysis in Northern China, it has been suggested that increase in temperature and precipitation could enhance vegetation growth, especially the grassland and cropland ecosystem, while PDSI is also an important limiting factor for vegetation growth.

$\Sigma$ NDVI versus climatic data anomaly slope trend analysis

To further analyze the time series trend consistency of $\Sigma$ NDVI and annual climatic data in different sub-regions, scatterplots of the regression slope values from annually $\Sigma$ NDVI and climatic data are subdivided into three zones (Northeast China, North China and Northwest China show in Fig. 1) (Fig. 7) to investigate the consistency in regression slope value at regional scale $(a=0.05)$. The four quadrangles (from one to four) in each regional plot represent positive precipitation, temperature, PDSI and $\Sigma$ NDVI $z$-score slope trend; positive $\Sigma$ NDVI but negative precipitation, temperature, PDSI $z$-score slope trend; negative $\Sigma$ NDVI and precipitation, temperature, PDSI $z$-score 


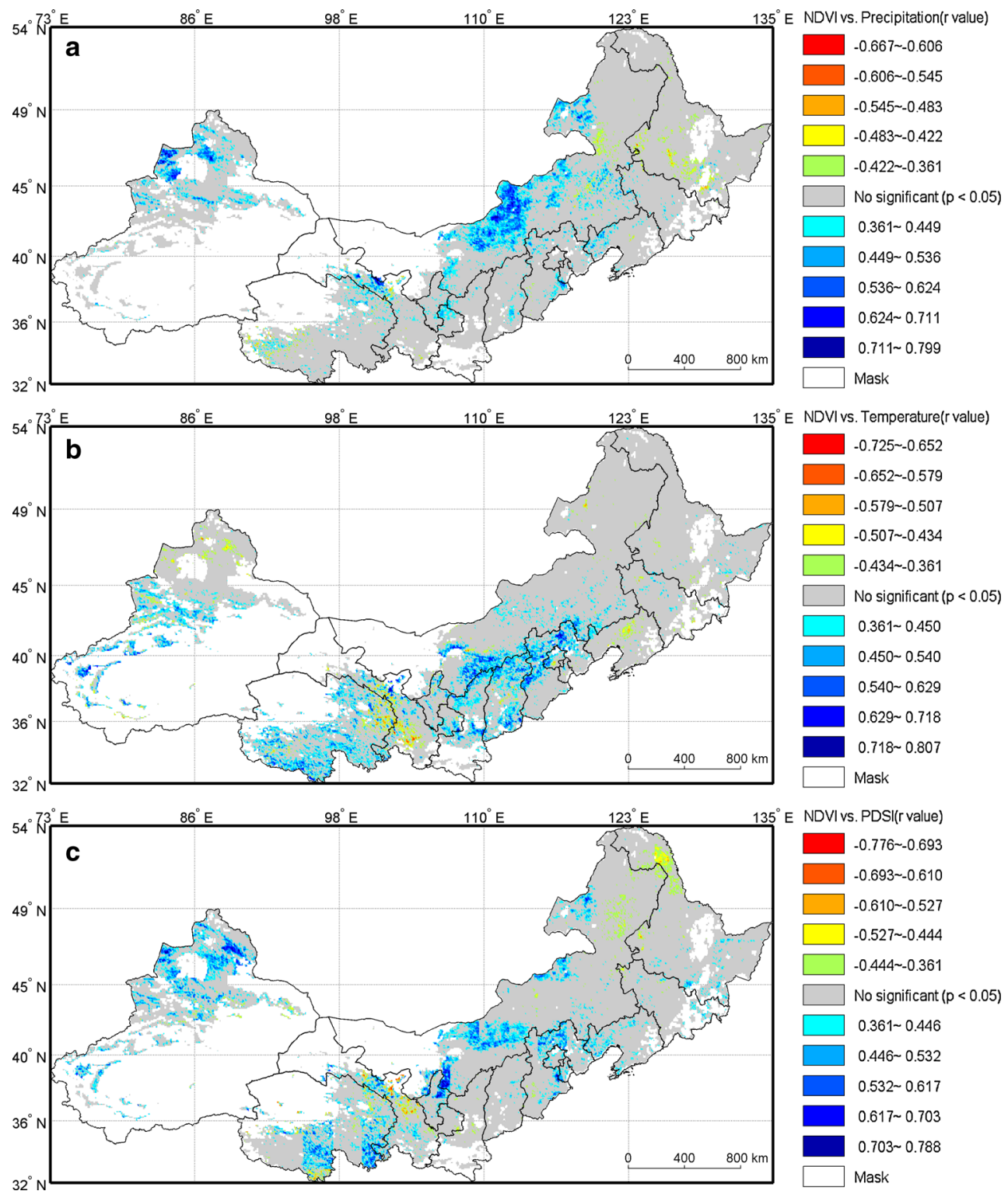

Fig. 5 Correlation coefficients of linear regression trend analysis for annually observations of a $\Sigma$ NDVI and precipitation, b $\Sigma$ NDVI and temperature, c $\Sigma$ NDVI and PDSI (1982-2011)

slope trend; positive precipitation, temperature, PDSI but negative $\Sigma$ NDVI $z$-score slope trend, respectively. For pixels with good agreement between $\Sigma$ NDVI and climatic data trends of scatterplots should be located in the first and third quadrants. However, Northern China and the three sub-regions are characterized by an increase or decrease from $\Sigma$ NDVI, precipitation, temperature and PDSI anomaly trends (Fig. 7a-c). Precipitation and PDSI in North China show a decreasing trend, while $\Sigma$ NDVI trends keep increasing (Fig. 7a, c). The vegetation response to precipitation and PDSI in Northwest China is more obvious than other regions. But for the entire Northern China region, the vegetation mainly showed positive greening trends. Only in a small part of the region vegetation decreases with increasing precipitation and PDSI. This implies that these areas are subject to land degradation, even desertification. Figure $7 \mathrm{~b}$ shows that there are pronounced changes of positive $\Sigma$ NDVI versus temperature in North and Northeast China. Precipitation decreases in North and Northeast China while greenness still increases partly due to temperature increase. A large area of vegetation greenness increase caused by warming and increased precipitation can be observed in Northwest China; however, warming contribution to vegetation greenness is larger (Fig. 7a, b). Though warming plays an important role in increasing vegetation greenness, the cooling effects of vegetation were found in few areas. This means that the greening in some areas can be explained by increasing temperature and 

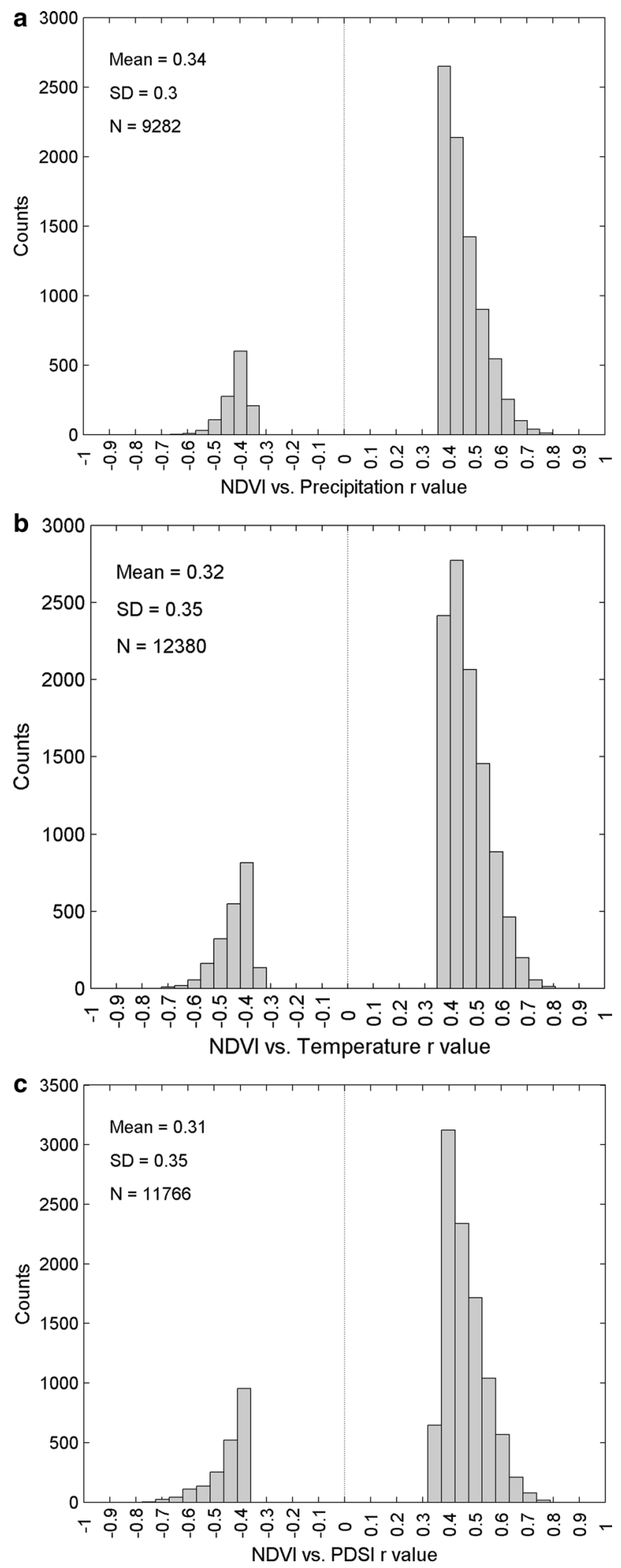

Fig. 6 Histograms of correlation coefficients calculated between a $\Sigma$ NDVI and precipitation, b $\Sigma$ NDVI and temperature, $\mathbf{c} \Sigma$ NDVI and PDSI $(p<0.05)$ precipitation as dominant factors. The results also suggest that the grassland and cropland ecosystem are becoming increasingly vulnerable to drought.

Many recent studies have documented a similar greening trend in Northern China since the early 1980s (Duan et al. 2011; de Jong et al. 2011; Fensholt et al. 2012; Xu et al. 2012). The results are supported by findings in this study that the Northern China has been characterized by a general increase in greenness for the period 1982-2011. Some other possible factors could be: (1) afforestation e.g. China has made some effort and launched a series of key national ecological engineering projects, such as the ThreeNorth Shelterbelt Project (1978-present), Beijing and Tianjin Sandstorm Source Treatment Project (2001-2010), Returning Farmlands to Forest Project (2003-present), and Returning Grazing Land to Grassland Project (2003present) (State Forestry Administration 2011; Wang et al. 2011, 2013). (2) Additional plausible explanations may include improved soil and water management, expansion of irrigation, rural exodus, changes in the use of fertilizer in cultivated areas and land reclamation (State Forestry Administration 2011; Fensholt et al. 2012).

However, land degradation is caused by different driving forces such as human activity pressure and adverse climatic effects. From previous studies, improper agricultural practices, overgrazing, mining, deforestation, and urbanization are the main human-made causes of land degradation or desertification ( $\mathrm{Li}$ et al. 2006; Bai et al. 2008; Bai and Dent 2009; State Forestry Administration 2011).

Comparison of $\Sigma$ NDVI versus climatic data anomaly for selected areas

Annually standardized $\Sigma$ NDVI, annual precipitation, temperature, and PDSI (average of a $3 \times 3$ grid cell window covering each year) from 1982 to 2011 are shown as time series in Fig. 8 for four selected locations corresponding to the four quadrants of Fig. 7. For all four locations the center coordinates are given. According to the results of the IGBP, the land cover of the locations 1, 2, 3 and 4 are cropland, frost, grassland, and grassland, as indicated in Fig. 2. Location 1 is in the west of Xinjiang Province $\left(80.8^{\circ} \mathrm{E}, 42.7^{\circ} \mathrm{N}\right)$ and shows an increasing $\Sigma$ NDVI trend respond to annual precipitation, temperature, and PDSI. The land cover of location 1 is "croplands". Although the location 1 has little precipitation and drought for a long time, the precipitation increases in recent years and vegetation turns green significantly. Location $2\left(100.7^{\circ} \mathrm{E}\right.$, $36.9^{\circ} \mathrm{N}$ ) is classified as "mixed forest" and characterized by a significant increase in $\Sigma$ NDVI while drought stress strengthened with warming significantly decreased 

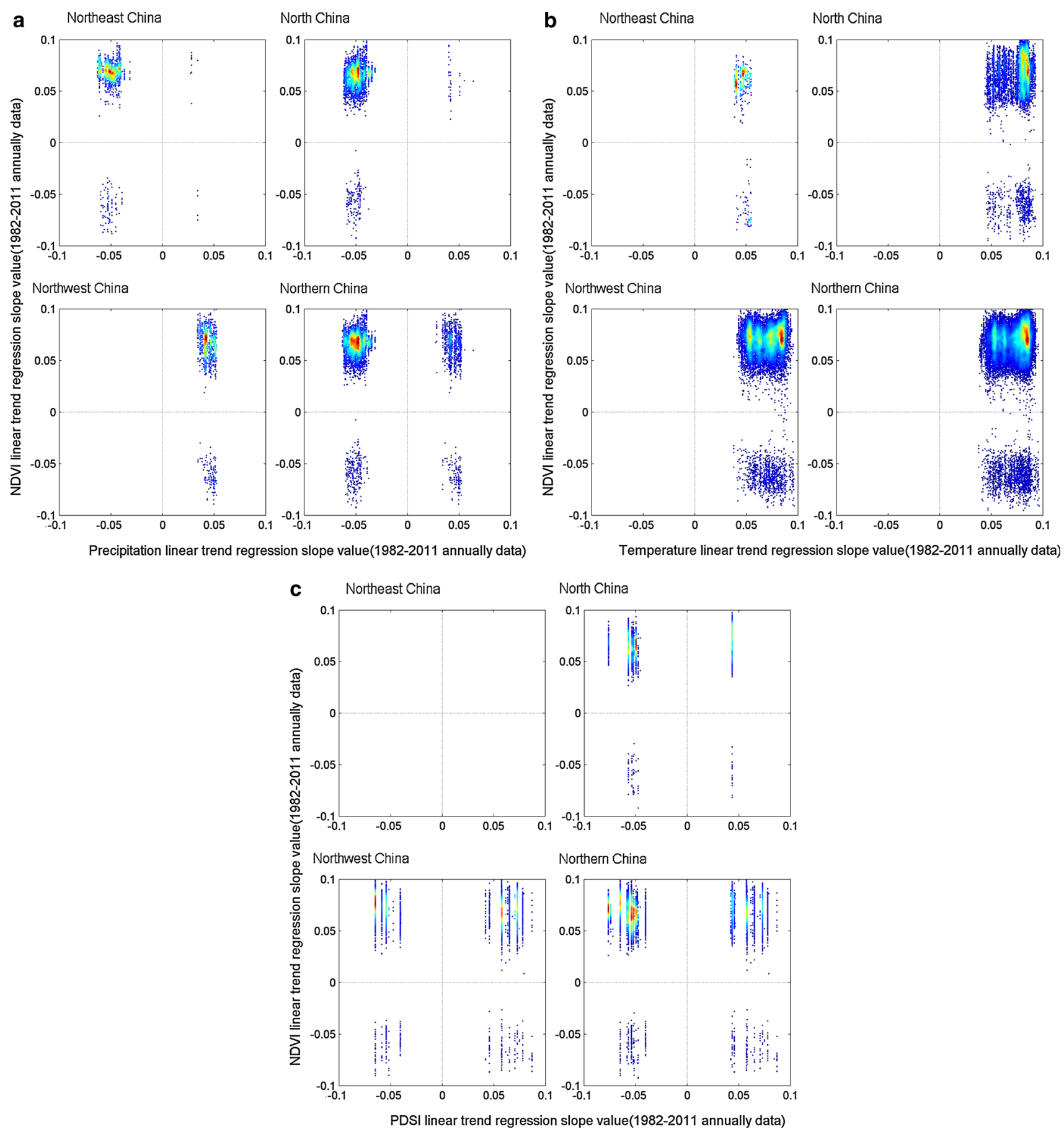

Fig. 7 Density scatterplot of a $\Sigma$ NDVI versus annual precipitation, $\mathbf{b} \Sigma$ NDVI versus temperature, $\mathbf{c} \Sigma$ NDVI versus PDSI linear trend regression slope values for the period of 1982-2011 $(\alpha=0.05)$

precipitation. Location 3 is in a region dominated by grassland (land cover class "grasslands") in the center of Inner Mongolia $\left(117.4^{\circ} \mathrm{E}, 45.3^{\circ} \mathrm{N}\right)$. There is a good agreement trend between $\Sigma$ NDVI and precipitation. This indicates that $\Sigma$ NDVI change in the location 3 is dominated by precipitation similar to location 1 . The land cover of location $4\left(120.9^{\circ} \mathrm{E}, 47.8^{\circ} \mathrm{N}\right)$ in the East of the Qinghai Lake is same as the location 3. That NDVI decrease with decreasing temperature in recent years shows that the location 4 is experiencing cooling effects. This analysis highlighted that the vegetation greenness change in the location 4 is dominated by temperature. 

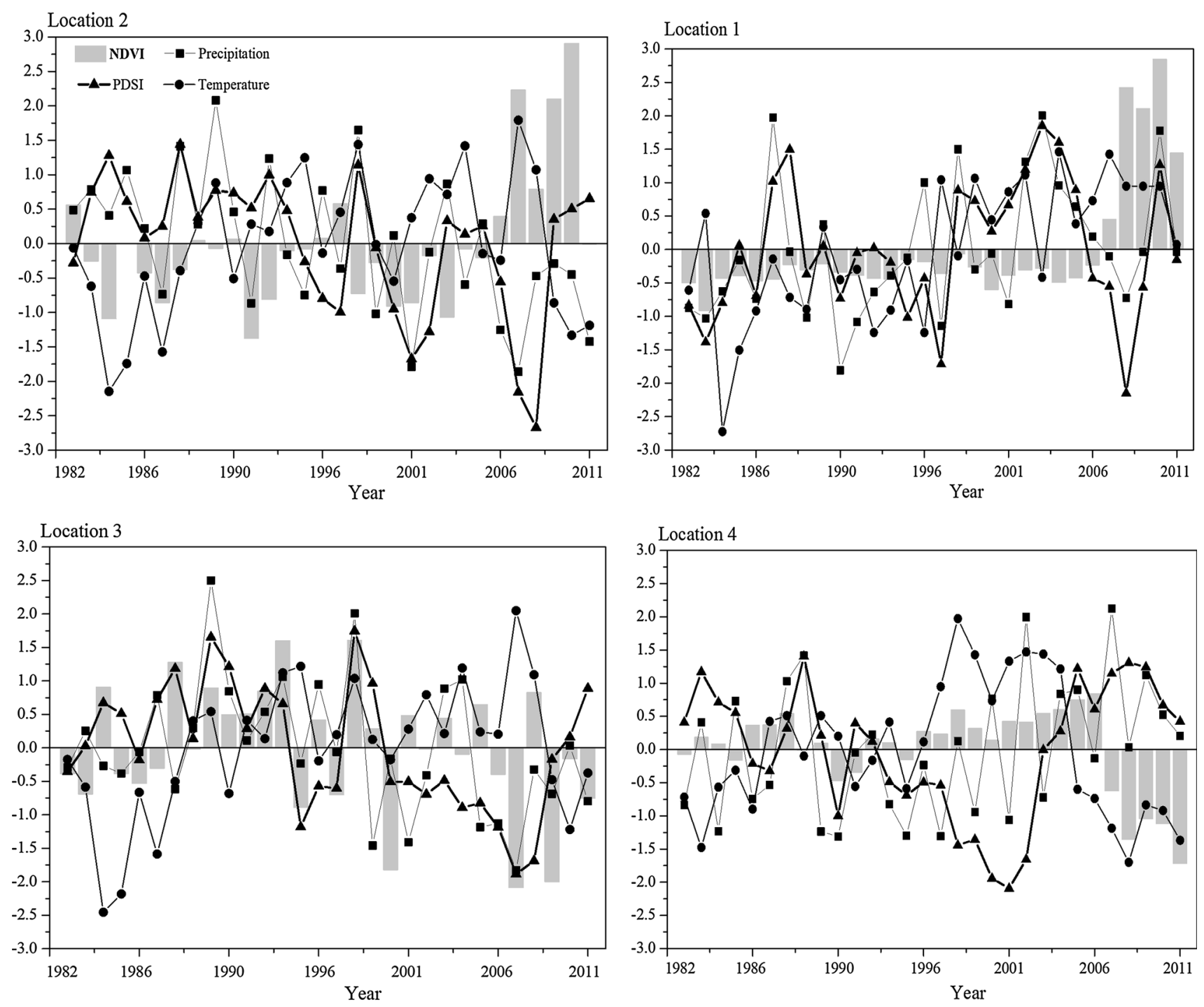

Fig. 8 Average $Z$-scores (expressed as standard deviations) of $\Sigma$ NDVI, annual precipitation, temperature, and, PDSI corresponding to the four quadrants of Fig. 6 . The $\Sigma$ NDVI, annual precipitation,

\section{Conclusion}

Time-integrated NDVI ( $\Sigma$ NDVI) from the GIMMS and MODIS NDVI time series data provided a reasonable estimate of total biomass produced in response to precipitation in Northern China. Based on these data, characterizing land condition has become complex with regions of both positive trends and mixed trends in Northern China. However, strong increase in greenness was observed over large areas of the Northern China during the period of 1982-2011 from the NDVI data. The significant greenness with a belt of high positive slope values across Daxingan Mountains, eastern Liaoning, and the Loess Plateau extends to the Qilian Mountains and southern Qinghai, and Xinjiang, Tianshan Mountains. Local land degradation was temperature, and PDSI values for the selected four locations are the average of a $3 \times 3$ grid cell window covering each year

found in Liao River Plain, Inner Mongolia, Beijing, Tianjin, Hebei southern, central Shanxi, and Xinjiang. This study shows that the strong increase in greenness trend of vegetation over the past three decades across the Northern China could be explained by increasing temperature and precipitation. However, the grassland and cropland ecosystem are becoming increasingly vulnerable to drought. The increase or decrease in the $\Sigma$ NDVI cannot be explained by climatic factors may be the consequence of human activities.

However, the greenness and potential of desertification are influenced by the synthetic interaction of climate factors and human activities. Such a coarse resolution remote sensing imagery like AVHRR GIMMS NDVI is suitable for monitoring land cover changes at relatively large scales 
while it has a limited explanatory power for a smaller scale. High resolution data (e.g. Landsat TM/ETM + images) and other factors (e.g. snow, runoff, evapotranspiration, water shortage, etc.) are needed as auxiliary to enhance our understanding of these trends.

Acknowledgments This paper was supported by Key Research Program of the Chinese Academy of Sciences (Grant No. KZZD-EW14), National Natural Science Foundation of China (41071278 and 41171334), Ecological Innovation and Breeding Project (Y254021031, 355031061), USDA NIFA Project (2010-3426321075). The authors thank GIMMS (the NASA Global Inventory Modeling and Mapping Studies) group and NASA/MODIS Land Discipline Group for sharing the GIMMS NDVI and MODIS LAND data. We would like to the comments from the anonymous reviewers, which helped to improve this manuscript.

\section{References}

Bai ZG, Dent D (2009) Recent land degradation and improvement in China. AMBIO 38(3):150-156

Bai ZG, Dent DL, Olsson L, Schaepman ME (2008) Proxy global assessment of land degradation. Soil Use Manage 24(3):223-234

Bayramov E, Buchroithner MF, McGurty E (2012) Determination of main climate and ground factors controlling vegetation cover regrowth along oil and gas pipelines using multiple, spatial and geographically weighted regression procedures. Environ Earth Sci 66(7):2047-2062

Bégué A, Vintrou E, Ruelland D, Claden M, Dessay N (2011) Can a 25-year trend in Soudano-Sahelian vegetation dynamics be interpreted in terms of land use change? A remote sensing approach. Glob Environ Chang 21(2):413-420

Cao XM, Chen X, Bao AM, Q W (2011) Response of vegetation to temperature and precipitation in Xinjiang during the period of 1998-2009. JAL 3(2):94-103

Dai A (2011) Characteristics and trends in various forms of the Palmer Drought Severity Index during 1900-2008. J Geophys Res (1984-2012) 116:D12115

de Jong R, de Bruin S, de Wit A, Schaepman ME, Dent DL (2011) Analysis of monotonic greening and browning trends from global NDVI time-series. Remote Sens Environ 115(2):692-702

Dong J, Tao F, Zhang G (2011) Trends and variation in vegetation greenness related to geographic controls in middle and eastern Inner Mongolia China. Environ Earth Sci 62(2):245-256

Duan H, Yan C, Tsunekawa A, Song X, Li S, Xie J (2011) Assessing vegetation dynamics in the three-north shelter forest region of China using AVHRR NDVI data. Environ Earth Sci 64(4): 1011-1020

Fensholt R, Rasmussen K (2011) Analysis of trends in the Sahelian 'rain-use efficiency' using GIMMS NDVI, RFE and GPCP rainfall data. Remote Sens Environ 115(2):438-451

Fensholt R, Sandholt I, Stisen S, Tucker C (2006) Analysing NDVI for the African continent using the geostationary meteosat second generation SEVIRI sensor. Remote Sens Environ 101(2):212-229

Fensholt R, Rasmussen K, Nielsen TT, Mbow C (2009) Evaluation of earth observation based long term vegetation trends-intercomparing NDVI time series trend analysis consistency of Sahel from AVHRR GIMMS, Terra MODIS and SPOT VGT data. Remote Sens Environ 113(9):1886-1898

Fensholt R, Langanke T, Rasmussen K, Reenberg A, Prince SD, Tucker C, Scholes RJ, Le QB, Bondeau A, Eastman R, Epstein H, Gaughan AE, Hellden U, Mbow C, Olsson L, Paruelo J,
Schweitzer C, Seaquist J, Wessels K (2012) Greenness in semiarid areas across the globe 1981-2007-an Earth Observing Satellite based analysis of trends and drivers. Remote Sens Environ 121:144-158

Helldén U, Tottrup C (2008) Regional desertification: a global synthesis. Glob Planet Change 64(3-4):169-176

Hickler T, Eklundh L, Seaquist JW, Smith B, Ardö J, Olsson L, Sykes MT, Sjöström M (2005) Precipitation controls Sahel greening trend. Geophys Res Lett 32(21):L21415

Huber S, Fensholt R, Rasmussen K (2011) Water availability as the driver of vegetation dynamics in the African Sahel from 1982 to 2007. Glob Planet Change 76(3):186-195

Li YC, Gong P, Liu CX, Chen J, Yu DY (2006) Vegetation cover changes and correlation with climatic factors in Northern china during 1982-1999. Resour Sci 28(2):109-117

Liu S, Wang T (2012) Climate change and local adaptation strategies in the middle Inner Mongolia, Northern China. Environ Earth Sci 66(5):1449-1458

Liu S, Wang T, Guo J, Qu J, An P (2010) Vegetation change based on SPOT-VGT data from 1998 to 2007, Northern China. Environ Earth Sci 60(7):1459-1466

Liu W, Cai T, Ju C, Fu G, Yao Y, Cui X (2011) Assessing vegetation dynamics and their relationships with climatic variability in Heilongjiang Province, northeast China. Environ Earth Sci 64(8):2013-2024

Mao DH, Wang ZM, Luo L, Ren CY (2012) Integrating AVHRR and MODIS data to monitor NDVI changes and their relationships with climatic parameters in Northeast China. Int $\mathbf{J}$ Appl Earth Obs 18:528-536

Martínez B, Gilabert M, García-Haro F, Faye A, Meliá J (2011) Characterizing land condition variability in Ferlo, Senegal (2001-2009) using multi-temporal 1-km apparent green cover (AGC) SPOT vegetation data. Glob Planet Change 76(3):152-165

Mitchell TD, Jones PD (2005) An improved method of constructing a database of monthly climate observations and associated highresolution grids. Int J Climatol 25(6):693-712

Mohammat A, Wang X, Xu X, Peng L, Yang Y, Zhang X, Myneni RB, Piao S (2012) Drought and spring cooling induced recent decrease in vegetation growth in Inner Asia. Agr Forest Meteorol 178-179:21-30

Mu SJ, Li JL, Chen YJ, Gang CC, Zhou W, Ju WM (2012) Spatial differences of variations of vegetation coverage in Inner Mongolia during 2001-2010. Acta Geogr Sin 69(9):1255-1268

Nemani RR, Keeling CD, Hashimoto H, Jolly WM, Piper SC, Tucker CJ, Myneni RB, Running SW (2003) Climate-driven increases in global terrestrial net primary production from 1982 to 1999 . Science 300(5625):1560-1563

Olsson L, Eklundh L, Ardö J (2005) A recent greening of the Saheltrends, patterns and potential causes. J Arid Environ 63(3):556-566

Peng S, Chen A, Xu L, Cao C, Fang J, Myneni RB, Pinzon JE, Tucker CJ, Piao S (2011) Recent change of vegetation growth trend in China. Environ Res Lett 6(4):044027

Piao SL, Wang XH, Ciais P, Zhu B, Wang TAO, Liu JIE (2011) Changes in satellite-derived vegetation growth trend in temperate and boreal Eurasia from 1982 to 2006. Glob Change Biol 17(10):3228-3239

Prince SD, Colstoun D, Brown E, Kravitz L (1998) Evidence from rain-use efficiencies does not indicate extensive Sahelian desertification. Glob Change Biol 4(4):359-374

Solano R, Didan K, Jacobson A, Huete A (2010) MODIS vegetation indices (MOD13) C5 user's guide. (Available at: http://vip. arizona.edu/MODIS_UsersGuide.php)

Song Y, Achberger C, Linderholm HW (2011) Rain-season trends in precipitation and their effect in different climate regions of China during 1961-2008. Environ Res Lett 6(3):034025 
State Forestry Administration (SFA) (2011) A bulletin of status quo of desertification and sandification in China, $\mathrm{p} 11$

Symeonakis E, Drake N (2004) Monitoring desertification and land degradation over sub-Saharan Africa. Int J Remote Sens 25(3):573-592

Tabari H, Marofi S, Aeini A, Talaee PH, Mohammadi K (2011) Trend analysis of reference evapotranspiration in the western half of Iran. Agr Forest Meteorol 151(2):128-136

Tian H, Wen J, Wang C, Liu R, Lu D (2012) Effect of pixel scale on evapotranspiration estimation by remote sensing over oasis areas in north-western China. Environ Earth Sci 67(8):2301-2313

Tucker CJ, Pinzon JE, Brown ME, Slayback DA, Pak EW, Mahoney R, Vermote EF, El Saleous N (2005) An extended AVHRR 8-km NDVI dataset compatible with MODIS and SPOT vegetation NDVI data. Int J Remote Sens 26(20):4485-4498

UNCCD (1994) Elaboration of an international convention to combat desertification in countries experiencing serious drought and/or desertification, particularly in Africa. United Nations General Assembly, 93rd plenary meeting, New York

Wang X, Chen F, Hasi E, Li J (2008) Desertification in China: an assessment. Earth-Sci Rev 88(3):188-206

Wang S, Wang Z, Piao S, Fang J (2010) Regional differences in the timing of recent air warming during the past four decades in China. Chinese Sci Bull 55(19):1968-1973

Wang Q, Zhang B, Dai SP, Zou Y, Ma ZH, Zhang YN (2011) Dynamic changes in vegetation coverage in the three-north shelter forest program based on GIMMS AVHRR NDVI. Resour Sci 33(8):1613-1620

Wang T, J-g Sun, Han H, C-z Yan (2012) The relative role of climate change and human activities in the desertification process in Yulin region of northwest China. Environ Monit Assess 184(12):7165-7173
Wang F, Pan X, Wang D, Shen C, Lu Q (2013) Combating desertification in China: Past, present and future. Land Use Policy 31:311-313

Xiao XM, Braswell B, Zhang QY, Boles S, Frolking S, Moore Iii B (2003) Sensitivity of vegetation indices to atmospheric aerosols: continental-scale observations in Northern Asia. Remote Sens Environ 84(3):385-392

Xu X, Piao S, Wang X, Chen A, Ciais P, Myneni RB (2012) Spatiotemporal patterns of the area experiencing negative vegetation growth anomalies in China over the last three decades. Environ Res Lett 7(3):035701

Yang X, Zhang K, Jia B, Ci L (2005) Desertification assessment in China: an overview. J Arid Environ 63(2):517-531

Yao Y, Qin Q, Fadhil AM, Li Y, Zhao S, Liu S, Sui X, Dong H (2011) Evaluation of EDI derived from the exponential evapotranspiration model for monitoring China's surface drought. Environ Earth Sci 63(2):425-436

Yin H, Li ZG, Wang YL, Cai F (2011) Assessment of desertification using time series analysis of hyper-temporal vegetation indicator in Inner Mongolia. Acta Geogr Sin 66(5):653-661

Zhang B, Wu D, Zhang L, Jiao Q, Li Q (2012) Application of hyperspectral remote sensing for environment monitoring in mining areas. Environ Earth Sci 65(3):649-658

Zhang BQ, Wu P, Zhao X, Wang Y, Gao X (2013) Changes in vegetation condition in areas with different gradients (1980-2010) on the Loess Plateau China. Environ Earth Sci 68(8):2427-2438

Zhu W, Lv A, Jia S (2011) Spatial distribution of vegetation and the influencing factors in Qaidam Basin based on NDVI. JAL $3(2): 85-93$ 